\title{
EDITORIAL
}

\section{Guidelines for assessing and treating suicidal individuals: toward validated approaches for difficult clinical cases}

\author{
Maurizio Pompili iD \\ Department of Neurosciences, Mental Health, and Sensory Organs, Faculty of Medicine and Psychology, Suicide Prevention Centre, \\ Sant'Andrea Hospital, Sapienza University of Rome, Rome, Italy.
}

Suicide prevention is a relatively young discipline. After thousands of years, it was only about a century ago that the first steps were taken to save the lives of those who wished to die. Such activities, mostly motivated by the initiative of single individuals, inspired interest from both clinicians and volunteers. However, these efforts were a preliminary approach. Only with the opening of the Los Angeles Suicide Prevention Center, acting as a prototype for the launch of many more such centers, did suicide prevention become prominent. Three pioneers in the field invented suicidology, and for the first time, suicide prevention was recognized as a major need in public health. ${ }^{1}$ One of the main pillars of such pioneering efforts was the development of the psychological autopsy. It appeared that a sizable percentage of deaths (10-15\%) are equivocal regarding their mode, and most of these are eventually certified as accidental, without adequate psychological investigation. Some of these uninvestigated equivocal deaths are, in fact, suicides. Certification of equivocal deaths usually lacks any attempt to establish the deceased's intention concerning their own demise. Uncertainty about the correct certification is particularly accentuated when the victim's intention is ambivalent, with coexisting wishes to both live and die; when the selfdestructive action is in itself inconclusive; or when death follows the action after a considerable delay. ${ }^{2}$

Most importantly, a psychological autopsy helps to recognize what we still call "warning signs," which can alert other people that a specific individual wishes to die. Such signs are most often divided into signs connected to talking about suicide (someone talking or writing about death, dying, or suicide when these actions are out of the ordinary for that person; threatening to hurt or kill oneself or talking of wanting to hurt or kill oneself), behavioral signs (uncontrolled anger; seeking revenge; acting reckless or engaging in risky activities seemingly without thinking; feeling trapped, as if there is no way out; increased alcohol or drug use; sleep problems, including insomnia; giving away prized possessions; visiting or calling people to say goodbye; isolation from family and friends, etc.), and signs connected to mood (dramatic

Correspondence: Maurizio Pompili, Department of Neurosciences, Mental Health and Sensory Organs, Suicide Prevention Center, Sant'Andrea Hospital, Sapienza University of Rome, 1035-1039, Via di Grottarossa, 00189 Rome, Italy.

E-mail: maurizio.pompili@uniroma1.it

Submitted Jan 29 2021, accepted Feb 04 2021, Epub Mar 222021. mood changes, rage, depression, loss of interest, humiliation, irritability, etc.). Warning signs are most helpful because they may add considerable emphasis to the assessment of high suicide risk rather than risk factors that often yield too many false positives. Over the past decades, the assessment of suicide risk has become part of clinical practice, especially in mental health. The documentation of such assessment and the implementation of a therapeutic plan is necessary to provide a suitable standard of care and reduce the risk of medicolegal action. $^{3}$ Furthermore, as suicide assessment groups together all possible factors, both risk and protective, to elucidate how these factors interact and what resources can be mobilized to protect the individual, scholars introduced the concept of formulation of suicide risk to provide a comprehensive judgment of each suicidal individual.

The multifactorial nature of suicide risk also places emphasis on avoiding single entities to explain a complex phenomenon. Psychiatric disorders are major contributing factors to suicide risk, but cannot explain this risk per se. Instead, understanding a single individual's suffering is essential in fine-tuning one's insight into the inner, private world of suicidal individuals. ${ }^{4,5}$ The concept of mental pain has become a necessary construct for introducing such suffering into subjects' minds. The perturbed mind hosts negative emotions and an inner dialogue through which suicide becomes the way out for unbearable mental pain. Thus, suicidal individuals wish to live, but they see death as an escape from overwhelming suffering.

Saving lives from such a perspective is a challenge, but also leads to great professional and human gratification. Empathy is important, but we also need proper treatments. Pharmacological therapy is essential for reducing suffering, hopefully in a short period of time. In this regard, first lithium and then atypical antipsychotics provide significant help for reducing suicide risk. Psychotherapy also provides a necessary treatment avenue and the opportunity to resolve conflicts, sometimes referred to at several previous instances. Somatic therapy also offers further opportunities for the treatment of suicidal individuals.

How to cite this article: Pompili M. Guidelines for assessing and treating suicidal individuals: toward validated approaches for difficult clinical cases. Braz J Psychiatry. 2021;43:465-466. http://dx.doi.org/ 10.1590/1516-4446-2021-1781 
I praise the two articles representing the Brazilian Psychiatric Association guidelines for the management of suicidal behavior. ${ }^{6,7}$ Undoubtedly, this effort appears to be comprehensive, timely, and most needed for clinicians. Guidelines have come to represent an important clinical tool, introducing a shared language that points to the standard of care when dealing with suicidal individuals. Such an approach now provides important protection from lawsuits. However, clinicians should not forget that guidelines must always place individuals first, and that an open-minded human approach, free from strict diagnostic criteria, must always prevail when seeking to unlock the suicidal mind.

\section{Disclosure}

In the last 3 years, MP has received lecture or advisory board honoraria or engaged in clinical trial activities with Allergan, Angelini, Italfarmaco, Janssen, Lundbeck, MSD, and Otsuka Corporations, all of which are unrelated to this report.

\section{References}

1 Litman RE, Shneidman ES, Farberow NL. Los Angeles suicide prevention center. Am J Psychiatry. 1961;117:1084-7.

2 Litman RE, Curphey TJ, Shneidman ES, Farberow NL, Tabachnick N. The psychological autopsy of equivocal deaths. In: Shneidman ES, Farberow NL, Litman RE, eds. The psychology of suicide. Scranton: Science House; 1970 . p. 485-96.

3 Simon RI. Psychiatrists awake! Suicide risk assessments are all about a good night's sleep. Psychiatr Ann. 1998;28:479-85.

4 Pompili $M$. The increase of suicide rates: the need for a paradigm shift. Lancet. 2018;392:474-5.

5 Pompili M. Critical appraisal of major depression with suicidal ideation. Ann Gen Psychiatry. 2019;18:7.

6 Baldaçara L, Rocha GA, Leite VS, Porto DM, Grudtner RR, Díaz AP, et al. Brazilian Psychiatric Association guidelines for the management of suicide behavior. Part 1. Risk factors, protective factors, and assessment. Braz J Psychiatry. 2021;43:525-37.

7 Baldaçara L, Grudtner RR, Leite VS, Porto DM, Robis KP, Fidalgo TM, et al. Brazilian Psychiatric Association guidelines for the management of suicidal behavior. Part 2. Screening, intervention, and prevention. Braz J Psychiatry. 2021;43:538-49. 